\title{
As novas traduções de Freud feitas diretamente do alemão: estilo e terminologia
}

\author{
Pedro Heliodoro de Moraes Branco Tavares*
}

\begin{abstract}
In 2009, seventy years after Sigmund Freud's death, his work went into the public domain. As a consequence, after decades of intense critics on the only and indirect translation available in Portuguese, we finally have in Brazil three translation projects of his writings being developed directly from the original in German. The intention of this article is therefore to discuss about the challenges and directions taken by these translators, above all, concerning the difficult task of compromising Freud's acclaimed literary style with a precise recuperation of his psychoanalytical terminology. As an example, we conclude by investigating the choices taken to translate Trieb, one of the most important of Freudian concepts.
\end{abstract}

Keywords: Sigmund Freud; Freud's translation; Translation and Psychoanalysis; Trieb.

Resumo: Em 2009, 70 anos após a morte de Sigmund Freud, sua obra caiu em domínio público. Como consequência, após décadas de intensas críticas sobre a única e indireta versão disponível em língua portuguesa, tem-se finalmente três projetos de tradução sendo desenvolvidos no Brasil a partir do original alemão. A intenção deste artigo, portanto, foi a de discutir os desafios e as direções tomadas por esses tradutores, sobretudo no que concerne à difícil tarefa de conciliar o aclamado estilo literário de Freud e uma precisa recuperação de sua terminologia psicanalítica. A título de exemplo, finalizou-se investigando as escolhas feitas para a tradução de Trieb, um dos mais centrais conceitos freudianos.

Palavras-chave: Sigmund Freud; Tradução de Freud; Tradução e Psicanálise: Trieb.

\footnotetext{
* Professor nomeado para a Área de Alemão DLM-FFLCH-USP. Doutor em Psicanálise e Psicopatologia - Université Paris VII. Doutor em Teoria Literária - UFSC. Pós-doutorando em Estudos da Tradução - PGET/ UFSC. Email: pedrohmbt@hotmail.com.
} 
Tavares, P. H. M. B. - As novas traduções de Freud feitas diretamente do alemão: estilo e terminologia

Sigmund Freud, fundador-idealizador da psicanálise, legou-nos uma expressiva obra que, sem dúvidas, revolucionou não somente as ciências clínicas, mas a própria cultura e a noção de sujeito na virada do século XIX para o século XX. Suas proposições inovadoras e controversas, seus pontos de vista a respeito do psiquismo e da cultura causaram em sua época, e ainda hoje causam, celeuma e discussões de cunho hermenêutico e epistemológico mesmo entre os leitores que puderam ter acesso à sua obra no idioma original (texto-fonte): o alemão.

Ao longo do século $X X$, porém, à medida que sua obra era traduzida para outras línguas europeias modernas e também à medida que avançavam as recepções da psicanálise nos meios acadêmicos e nos institutos de formação, questões concernentes à tradução passaram a se confundir com uma dinâmica de poder institucional. Conforme 0 viés dado às traduções, sobretudo àquelas que privilegiaram um rigor conceitual acima da manutenção do estilo freudiano, passou-se a observar uma crescente disputa entre os freudianos quanto a quem, em que língua, ter-se-ia mantido mais fiel à obra do mestre.

A mais influente empresa de tradução da totalidade das obras de Freud deu-se na Inglaterra, a cargo do casal J ames e Alix Strachey, que verteram a obra de Freud do alemão ao inglês sob a supervisão teórica e tutela do então principal representante político do freudismo naquele país: Ernest J ones. 0 preço pago por esse pioneirismo foi uma considerável crítica, sobretudo das escolas francesas de psicanálise que apontaram na Standard Edition dos Strachey um viés excessivamente médico-biológico para a obra de um pensador que, mesmo tendo suas origens na clínica médica, gradativamente dela se afastou para ser um intelectual e pensador do sujeito e da cultura mediados pela linguagem, pelo simbólico.

$\mathrm{Na}$ verdade, apesar da repercussão dessas críticas ser muito mais vultosa na França e na América Latina, a mais emblemática reprimenda a essa tradução foi feita nos Estados Unidos com a publicação de Freud and Man's 
Tavares, P. H. M. B. - As novas traduções de Freud feitas diretamente do alemão: estilo e terminologia

Soul de Bruno Bettelheim. Esse psicanalista vienense radicado nos Estados Unidos via que o Freud vertido para o inglês perdera seu potencial humanista, transformando-se em um autor tecnicista.

A explicação provável não é a leviandade ou negligência dos tradutores, mas um desejo deliberado de perceber Freud estritamente dentro do quadro da medicina e, possivelmente, uma tendência inconsciente a se distanciarem do impacto emocional daquilo que Freud procurou transmitir (BETTELHEIM 1982).

Fortemente influenciada pela leitura que J ACQUES LACAN (1901-1981) propôs em meados do século XX - do que ele chamou de "retorno a Freud", a partir de recursos como a linguística estrutural de Ferdinand de Saussure -, a intelectualidade francofônica propôs a necessidade de recuperar em Freud o rigor dos elementos de linguagem, sobrepondo o simbólico ao enfoque médico e positivista dado pelos britânicos e norte-americanos. Diante dessa necessidade surge a tradução dirigida por J ean Laplanche, Pierre Cotet e André Bourguignon, fortemente influenciada pelas ideias dos intelectuais franceses em voga no período. Essa tradução, influenciada pelas apropriações lacanianas da linguística de Saussure, primou pela "fidelidade ao significante", tornando-se uma tradução "terminológica", sobrepondo o conceitual ao estilo do autor. Para esses tradutores, expressamente: "A exatidão inclui a recusa do embelezamento e da reparação" (BouRguiGnON et al. 1989). Entretanto, esses tradutores sofrerão pesadas críticas por não levarem, muitas vezes, em consideração o não isomorfismo lexical entre as línguas alemã e francesa. 0 exemplo mais patente é o caso de Angst traduzido invariavelmente por angoisse (angústia), mesmo quando sua conotação claramente seria a de peur (medo) ou anxiété (ansiedade).

Casos semelhantes, de discussão quanto aos critérios de tradução, ocorreram com outras importantes traduções para idiomas europeus como, por exemplo, o espanhol. Ainda que com uma repercussão muito menor em um primeiro momento, foi neste idioma que se viu uma primeira empresa de 
Tavares, P. H. M. B. - As novas traduções de Freud feitas diretamente do alemão: estilo e terminologia

tradução pretendendo a totalidade dos escritos freudianos. Trata-se da tradução intitulada Sigmund Freud - Obras Completas, do espanhol Luís Lopez-Ballesteros y de Torres, fomentado pelo filósofo Ortega y Gasset realizada entre 1922 e 1938 (VILLAREaL in Orston 1992). Bastante incompleta e com muitas imprecisões, esta edição foi revista e ampliada pelo argentino Ludovico Rosenthal, na década de 1950.

Tantas correções provocaram na Argentina, talvez o mais freudiano dos países, o debate sobre a importância de uma nova versão. Em tempo recorde, entre 1978 e 1982, J osé Luis Etcheverry produziu para a Editora Amorrortu uma tradução criteriosa e, ainda que sem os exageros e as inflexibilidades da versão francesa, bastante preocupada com a fidelidade terminológica, sem esquecer aspectos estilísticos, mesmo que os deixasse em segundo plano (WolfSON 2006). Esta é, sem dúvida, a versão mais consultada no Brasil pelos estudiosos de Freud que não têm acesso ao seu idioma original e que encontram, portanto, na castelhana língua irmã uma forma de consolo. No Brasil, até muito recentemente, ficamos à mercê de traduções indiretas e de comparações entre critérios adotados em traduções para outras línguas. Um século depois da criação da psicanálise, a única versão da totalidade das obras de Freud, a Edição Standard Brasileira das Obras Psicológicas Completas, é uma tradução feita a partir da versão inglesa.

Quer dizer, até o final desse século, a única versão disponível em língua portuguesa aos brasileiros era uma "tradução de tradução", uma versão feita a partir da referida tradução de J ames e Alix Strachey. A versão dos Strachey divide os leitores de Freud, sendo aqueles criticados pelo viés ideológico que deram a Freud, sua tradução, porém, foi bastante elogiada pelo pioneirismo, organização, sistematização e, sobretudo, por um primoroso zelo. Seu aparato editorial (notas, prefácios, índices, glossários) foi parcial ou totalmente utilizado por praticamente todos os tradutores para outras línguas e veio a ser incorporado inclusive á Studienausgabe (Edição de Estudos) alemã. No caso da tradução brasileira, tradução dessa tradução, ela mostrou-se especialmente 
Tavares, P. H. M. B. - As novas traduções de Freud feitas diretamente do alemão: estilo e terminologia

problemática, não somente por ter sido feita de modo indireto, mas também por considerável debilidade em critérios e sistematização.

Para a tradutora Marilene CARone (1989), crítica mais mordaz dessa versão, Strachey não seria o problema:

\begin{abstract}
em momento algum os 'pecados' de Strachey são frutos da incompetência do tradutor ou do desconhecimento da língua de partida ou de chegada. São sempre expressões de uma intenção clara de apresentar a psicanálise dentro de determinada orientação ideológica (...). Mas com a edição brasileira não estamos sequer diante de uma tradução razoavelmente correta do inglês. É muito, muito pior (...). Trata-se pura e simplesmente de falta de competência e responsabilidade no trabalho intelectual. Com ela, temos a melancólica oportunidade de ver um escritor do porte de Freud falando como um personagem de filme dublado de televisão, cometendo erros crassos de português, usando uma linguagem retorcida e pedante, assumindo incoerências teóricas e às vezes fazendo afirmações inteiramente sem pé nem cabeça.
\end{abstract}

Atualmente, porém, com um século de atraso, surgem ao leitor brasileiro simultaneamente três novas traduções de Freud sendo, desta vez finalmente, traduções diretas do idioma original: o alemão. Este que certamente pode ser considerado um fato histórico de tradução, que testemunhamos a partir de 2010, apresenta claros motivos para a sua compreensão e também pontos fundamentais para reflexão e investigação.

0 motivo fundamental deste atraso parece simples: a editora brasileira que detinha os direitos autorais que agora, 70 anos após o falecimento de Freud (em 1939), caem em domínio público era também a que possuía os direitos da pioneira tradução dos Strachey para o inglês. Esta mesma editora, a Imago, cinco anos antes de a obra entrar em domínio público, lançou em 2004 um primeiro volume de uma primeira tradução elaborada diretamente do alemão (Obras Psicológicas de Sigmund Freud - Volume 1 - Escritos sobre a Psicologia do Inconsciente), a cargo de uma equipe coordenada pelo psicanalista e tradutor Luiz Hanns. 
Tavares, P. H. M. B. - As novas traduções de Freud feitas diretamente do alemão: estilo e terminologia

Hanns já era uma referência nacional quanto a Freud e sua terminologia original desde seu Dicionário Comentado do Alemão de Freud, publicado em 1996 pela mesma editora Imago do Rio de J aneiro. Neste caso, da tradução de Hanns, o atraso parece ser compensado por um inédito zelo e minúcia marcados pelas exaustivas referências e notas, além de longa introdução (45 páginas) dedicada aos Critérios de Tradução ali adotados. Trata-se aí de um fato sem precedentes mesmo nas famosas traduções para 0 francês ou para o espanhol. No caso do espanhol, Etcheverry chegou a elaborar um breve livro adicional à edição da Amorrortu sobre sua tradução, mas nada comparável ao que Hanns inseriu nos próprios volumes de suas traduções.

Em paralelo, porém, outro reconhecido tradutor brasileiro, Paulo César de Souza, vem elaborando outra versão das obras de Freud. Souza, que já duas vezes foi agraciado com o prêmio J abuti de tradução por suas versões diretas do idioma alemão ao português das obras de Brecht e Nietzsche, dedicou às traduções da obra de Freud sua tese de doutorado, posteriormente publicada pela Editora Ática sob o título As Palavras de Freud - O Vocabulário Freudiano e suas Versões (1999). A tradução de Souza veio a lume somente em 2010, com os quatro primeiros volumes (de 20 programados) publicados pela editora Companhia das Letras de São Paulo.

Uma terceira tradução da obra de Freud está a cargo de Renato Zwick, bacharel em filosofia e tradutor de autores filosóficos e literários de expressão alemã, pela editora L\&PM de Porto Alegre. Também no ano de 2010, esta editora publicou dois primeiros volumes da tradução de Zwick, desta vez de ensaios de Freud, a saber, 0 futuro de uma Ilusão (Die Zukunft einer Illusion) e O Mal-Estar na Cultura (Das Unbehagen in der Kultur).

Temos, portanto, três traduções ocorrendo simultaneamente em três localidades distintas do País. Diante deste fato ímpar para os estudos de tradução, já começamos a observar os efeitos de intensos debates, criações de grupos de estudos, embates entre defensores de uma das três traduções, 
Tavares, P. H. M. B. - As novas traduções de Freud feitas diretamente do alemão: estilo e terminologia

entre tantos outros fenômenos. A importância de fato é compreensível já que se trata de um autor que fez do simbólico e da linguagem o centro da experiência humana. Alguém que influencia com sua obra de forma tão contundente os Estudos de Tradução, a Literatura, a Análise de discurso, entre outros domínios intelectuais relacionados à linguagem, certamente, merece um criterioso debate a respeito de sua própria escrita.

O trabalho com a obra de Freud e sua transposição a outras línguas impõe aos seus tradutores desafios de recomposição de uma escrita complexa e multifacetada. Ao longo do desenvolvimento de sua teoria e técnica de trabalho, assiste-se ao concomitante desenvolvimento de Freud enquanto escritor. Não que desde o seu tempo de neurologista ou pesquisador de laboratório suas publicações científicas fossem menos elaboradas no que diz respeito a sua composição estilística. Mas, na passagem para a sua Metapsicologia (como denominou sua empresa teórica) e nas suas descrições de caso, os dotes de um Freud beletrista tomam um lugar de destaque. Sua preocupação em divulgar a psicanálise serve como subsídio para 0 aprimoramento de uma estilística elaborada, porém acessível, aproximandose de uma prosa científica. Ao mesmo tempo, suas obras como ensaísta e seus relatos de casos clínicos fizeram enriquecer sua capacidade de escritor imaginativo (Dichter) (TAVARES 2007).

Poderíamos dizer com ScHÖNAU (1968), portanto, que se fazia presente no criador da psicanálise uma espécie de natureza dupla em sua escrita. Uma espécie de prosa científica (Wissenschaftsprosa), com aspectos de uma "prosa-poético-imaginativa" (Dichtprosa), mas que apelando para a sensibilidade do leitor, através de recursos literários, procuraria transmitir conhecimentos e apelar para a razão. Aqui, aludimos à busca de conciliação de Freud entre o racional e o estético, admitindo o envolvimento estético de quem o lê desde que isso não prejudique a Ratio (SouzA 1998).

Walter Schönau, que exalta os dotes literários de Freud, de fato defende a tese de um Freud firmemente calcado na ciência, encontrando no 
Tavares, P. H. M. B. - As novas traduções de Freud feitas diretamente do alemão: estilo e terminologia

belo estilo não mais que um poderoso recurso comunicativo. "Estou ciente de que a concentração sobre 0 estético-literário oculta 0 perigo da desfiguração" (SCHÖNAU 1968). Para este autor, Freud não deve ser visto como escritor e sim como cientista. 0 "literário" em Freud "... trata-se aí de um fenômeno secundário (...) sem negar que ele exerça um papel nada marginal na estrutura global". Apesar destas fronteiras entre o científico e o estético nos parecerem hoje, de certo modo, ultrapassadas, cabe lembrar que certamente não o eram na virada para o século XX.

Diferente e muito mais ousada é a visão de Walter Muschg, que já em 1930 - mesmo ano, aliás, em que Freud é agraciado com o Premio Goethe publica o sugestivo ensaio Freud como Escritor (Freud als Schriftsteller), no qual sem negar seus dotes científicos apresenta-o como mestre da escrita. Este importante crítico literário suíço inicia seu ensaio dizendo que "O escritor Freud não pode ser separado do psicólogo..." e, sendo seu contemporâneo concluiu considerando-o, "um dos mais impositivos autores da Literatura (Schrifttum) atual” (MusCHG 1930).

0 estético aparece, de fato, em Freud como um importante recurso à teorização. Sua opção pelo elemento literário, que se manifesta seja nas numerosas epígrafes, citações ou analogias de suas construções teóricas com autores cuja obra se articula à instituição do estético, ou mesmo no estilo próprio de exposição de suas ideias, poderia ser observado como uma forma de travestir o discurso teórico, tal qual ocorre com o estilo de escrita comum a tantos autores da pós-modernidade (TAVARES 2007).

0 estilo freudiano, mais do que dar harmonia, beleza e clareza às suas construções teóricas, implica diretamente a elaboração dessas formulações. Tomando aqui a ideia de Francesco Adorno, distinguir estilo de conteúdo seria incorrer em um erro metodológico:

Se o estilo for uma 'distorção coerente' da linguagem, não é necessário somente considerá-lo como modo de expressão, mas é necessário analisá-lo como uma divergência em relação à norma 
Tavares, P. H. M. B. - As novas traduções de Freud feitas diretamente do alemão: estilo e terminologia

lingüística (sic) que também tem a capacidade para organizar o texto do pensamento. 0 'estilo' é, assim, uma maneira de caminhar, um gesto não textual, capaz também de organizar 'o texto de um pensamento' (ADORNo 1996).

Falar, porém, de um estilo de Freud como um misto de uma escrita que ora se vale do recurso do rigor e do convencimento, ora da figurabilidade e da fruição, seria um reducionismo injusto. A colocação de Freud como um dos maiores escritores do século XX justificar-se-ia se observássemos a riqueza de seu(s) estilo(s). Qualquer tentativa de rotulá-lo, deveria antes passar pela observação de seus tradutores franceses (LAPLANCHE, Cotet \& BouRGUIGNON 1989: 23-4) acerca do "elenco" de estilos manifestos em sua prosa:

- o filósofo e didata da metapsicologia;

- o dialético da Psicologia das Massas;

- o conferencista real ou imaginário das Conferências e das Novas Conferências;

- o ensaísta da Recordação de Infância de Leonardo da Vinci;

- o orador de Recordações Atuais sobre a Guerra e a Morte;

- o debatedor que encontra, em Totem e Tabu ou na Análise de uma Histeria, o movimento mesmo de uma reunião pública;

- o polemista da Contribuição à História do Movimento Psicanalítico;

- o procurador que aj usta as contas com J ung, Adler ou J anet;

- o panegirista de Charcot;

- o biógrafo ou exegeta de Moisés;

- o memorialista de si mesmo (Estudo Autobiográfico);

- o prefaciador de ao menos 15 obras de confrades;

- o linguista de "o Inquietante" (Das Unheimliche);

- o poeta das horas de graça concedida pela natureza ("A Transitoriedade"), pelo romance (Gradiva), pela comédia shakespeariana ("o Tema das Escolhas dos Cofrinhos");

- o cronista de seus próprios sonhos ou de seus lapsos, inclinado à confidência ou à confissão;

- o dialoguista que sabe fazer falar tanto o pequeno Hans, como o interlocutor parcial da "Análise Leiga";

- o contador das "Lembranças Encobridoras";

- o folhetinista da Viena burguesa, com suas ruas, suas moradias, seus pátios, suas escadas, suas alcovas; 
Tavares, P. H. M. B. - As novas traduções de Freud feitas diretamente do alemão: estilo e terminologia

- o miniaturista do "Bloco Mágico";

- o humorista que gosta de ditos espirituosos e analisa aqueles dos outros;

- o mestre do aforismo, de todas as formas de imagens, comparações e metáforas, do paralelo, da citação que ele explora ou do exergo de que se apropria.

Em suma, dizer que Freud era um talentoso escritor talvez em muito se deva a esta versatilidade, que impede qualquer definição estilística. 0 recorte que procuraremos evocar aqui, no entanto, será quanto à insistente preocupação que se encontra em sua prática, sua teoria e em seu estilo, de transpor do visual para as palavras e, em via contrária, como suas construções teóricas remetem à representação imagética, como é o caso dos recursos topológicos. Segundo sua própria teoria dos sonhos, as imagens oníricas que, no processo primário, estão associadas às palavras - ou talvez às representações-palavras - serão traduzidas, a partir do processo secundário, na busca das palavras que relatarão, e com isso interpretarão, o sonho como faz o decifrador de um rebus.

\begin{abstract}
Pensamentos do sonho e o conteúdo do sonho nos são dados como duas apresentações do mesmo conteúdo em duas línguas diferentes, ou melhor, o conteúdo do sonho aparece como uma transposição dos pensamentos de sonho em um outro modo de expressão cujos caracteres e leis sintáticas podemos conhecer através da comparação do original com a tradução. (Traumgedanken und Trauminhalt liegen vor uns wie zwei Darstellungen desselben Inhaltes in zwei verschiedenen Sprachen, oder besser gesagt, der Trauminhalt erscheint uns als eine Übertragung der Traumgedanken in eine andere Ausdrucksweise, deren Zeichen und Fügungsgesetze wir durch die Vergleichung von Original und Übersetzung kennen lernen können) (FREUD 1900).
\end{abstract}

Freud faz uso muito particular dos recursos imagéticos da língua alemã para tratar justamente, pelo exemplo da narrativa envolvendo o sonho, da transposição das imagens ao discurso. Neste sentido, demonstra o quanto 0 trabalho do analista é um trabalho de tradução (idem). 
Tavares, P. H. M. B. - As novas traduções de Freud feitas diretamente do alemão: estilo e terminologia

Sua versatilidade e sua erudição se destacam no estilo ou na escrita, porém, à diferença do que se possa pensar, a sua terminologia, os elementos fundamentais de sua metapsicologia, seus Grundbegriffe (conceitos fundamentais), eram muito mais "familiares" e "comuns" no contexto de sua cultura e língua de expressão do que se tende a imaginar a partir das traduções mais difundidas. Isso, aliás, para aqueles que têm contato com 0 seu pensamento no original alemão não é de se estranhar, uma vez que toda a problemática de sua obra e do tipo de "tratamento psíquico" que sugere é sobre e para as questões da vida cotidiana (FREUD 1901).

Se dizia que era necessário certo nível intelectual para se submeter à análise, estava se referindo à capacidade de abstração e de elaborar metáfora (de "traduzir" em última análise). Freud raramente quis fazer uso das chamadas "línguas clássicas", do latim e do grego, como recurso de autoridade cientificista, tal como se observa em aspectos da erudita tradução dos Strachey. Freud nunca falou em anáclise (anaclisis), e sim em apoio (Anlehnung), nunca mencionou um neologismo de origem grega como catexia (cathexis), mas tratou de algo acessível como a ideia de ocupação ou investimento (Besetzung).

O objetivo mais amplo, portanto, a partir deste artigo, foi 0 de fomentar a discussão sobre as interfaces entre Tradução e Psicanálise a partir de certas reflexões quanto à situação da tradução das obras de Freud no Brasil. O fato da elaboração das três novas traduções de Freud feitas diretamente do alemão foi proposto como ponto de partida para um tema muito mais amplo, a saber, o da interface entre Psicanálise e Tradução.

Desde a Traumdeutung, sua obra mestra, Freud compara 0 analista a uma espécie de "decifrador de hieróglifos" (Freud 1900) nos moldes de Champollion, que transpõe a linguagem do inconsciente a uma linguagem compreensível pela consciência. Ou para citarmos Mahony em seu Freud as a Writer, "o objetivo mais geral do analista é fazer, por meio de suas 
Tavares, P. H. M. B. - As novas traduções de Freud feitas diretamente do alemão: estilo e terminologia

traduções, a transposição do que é inconsciente para o que é consciente" (1987: 7).

Freud e a psicanálise nos lembram que "toda língua nos é estrangeira" (FREUD 1919), é uma lei na qual somos imersos por outro e a partir dos códigos de um outro. É neste estranho/ estrangeiro que constituiremos nossa morada. A esta questão Freud dedicou seu ensaio de caráter mais linguístico: Das Unheimliche (1919), no qual trabalhou exaustivamente as implicações deste significante composto pela negação (prefixo un-) ao familiar (heimlich), ao lar (Heim) e que dá conta paradoxalmente da "estranheza inquietante" provocada pelo que nos é próprio, ainda que vivido como "estrangeiro/ estranho" (fremd). Estranho e inquietante é tudo o que me toca e me diz respeito sem que eu possa para isso encontrar tradução.

A tradução tem uma relação intrínseca com a psicanálise, já que os primórdios das relações humanas são relações de tradução. "A tradução é sempre incompleta e cheia de falhas e tropeços como o próprio sujeito. 0 autor (...), a relação entre o tradutor e autor é conflituosa como a relação com o desejo ou a relação psicanalítica" (MONTEIRO, 2009: 43). Acredita-se que 0 debate entre estes fazeres oferece muitas possibilidades ainda inexploradas.

Como bem ilustra o título do artigo de Paulo César de Souza, Nosso Freud (SouzA 1986), a intenção do autor deste artigo foi lançar luz sobre um debate do quanto estas traduções contribuirão para uma apreensão direta da obra de Sigmund Freud, com ou sem interferências de uma terceira língua. Visou-se analisar as soluções encontradas para certas necessidades de escolhas com a qual o tradutor tradicionalmente se depara ao estabelecer suas ênfases ou critérios entre o estilo e a terminologia. Estas questões fundamentais estão citadas a seguir: 
Tavares, P. H. M. B. - As novas traduções de Freud feitas diretamente do alemão: estilo e terminologia

- Adaptação ou recriação da terminologia: se Sigmund Freud pretendeu com sua obra fundar uma disciplina científica, torna-se difícil precisar o que deve ser elevado à categoria de conceito e que opções de vocabulário (filosófico, médico, psicológico) no português deverão ser priorizadas em termos tais como: Ich (ego / eu), Es (id/isso), Besetzung (catexia / investimento / ocupação), Verdrängung (recalque / repressão / repulsão), Vorstellung (representação / ideia), Angst (angústia / medo / ansiedade), Verwerfung (rejeição / forclusão), Zwang (compulsão / coerção / obsessão), Versagung (frustração / impedimento) etc.

- Adaptação ou recriação de estilo: se Freud é tido como o pai da Psicanálise e o inventor de uma disciplina teórica, não devemos esquecer que ele foi agraciado com 0 Prêmio Goethe em reconhecimento ao seu talento como escritor e ensaísta. Se a necessidade de uma precisão quanto a sua terminologia é largamente debatida a partir dos diferentes partidários do freudismo, o maior prejuízo que acaba por se observar em decorrência desta busca por um purismo conceitual é a perda da fruição do texto e a elegância de seu estilo. Mister se faz, portanto, observar as estratégias de preservação ou reinvenção deste estilo.

- Adaptação ou recriação tendo outras línguas como interdiscurso: se a tradição do freudismo no Brasil foi e é fortemente influenciada pelas leituras prévias de autores influentes a partir de outras línguas como 0 inglês, o francês e o espanhol (dada a forte tradição psicanalítica argentina), deve-se observar de que modo os tradutores sofrerão estas influências ou optarão realmente por explorar de forma inédita os recursos da língua portuguesa.

Por certo que os debates sobre essas três traduções prometem ser intensos e talvez seja um tanto prematura a tentativa de uma ampla investigação enquanto dispomos de tão pouco material publicado. É importante esclarecer que até o momento não há nenhum texto de Freud que tenha sido traduzido e publicado pelos três tradutores em questão.

Mesmo assim, passemos agora para uma primeira exploração das direções tomadas a respeito do mais polêmico ponto concernente à tradução 
Tavares, P. H. M. B. - As novas traduções de Freud feitas diretamente do alemão: estilo e terminologia

de Freud em sua terminologia. Trata-se do conceito fundamental Trieb", que através da tradução indireta da Standard Brasileira tornou-se instinto. Nas críticas aos Strachey e sua "biologização" do texto freudiano, este, o uso de instinct (e não o de drive) para o Trieb é por certo o exemplo mais evidente. Em meio às décadas de espera por uma tradução direta, consagrou-se no Brasil através da forte influência francesa e lacaniana o termo pulsão (pulsion) como alternativa ao intensamente criticado instinto. Pulsão já encontra inclusive no Dicionário Houaiss da Língua Portuguesa a acepção psicanalítica:

substantivo feminino Rubrica: psicanálise. Processo dinâmico, força ou pressão, que faz o organismo tender para uma meta, a qual suprime 0 estado de tensão ou excitação corporal que é a fonte do processo. Obs. : cf. instinto (psicn.) (HoUAISS \& VILLAR 2001).

Nas três referidas traduções, encontramos três versões diferentes para este que é talvez o segundo (após o termo Unbewusste - inconsciente) mais central dos conceitos freudianos. Luiz Hanns adere aí à tradição predominante que através da influência francesa adotou o termo pulsão. Hanns não se declara plenamente satisfeito com a escolha. Aponta para o exagero daqueles que separam radicalmente as acepções de instinto e pulsão, já que o Trieb em certas acepções poderia ser tomado como sinônimo de instinkt, mesmo que esse dificilmente seja o caso nos usos freudianos do termo. Eis como 0 tradutor expõe a defesa de sua opção:

O termo "instinto" não foi adotado nesta tradução por ser mais estreito que Trieb e levar a uma compreensão mais desligada dos aspectos volitivos e representacionais também presentes em Trieb e fundamentais para uma compreensão psicodinâmica e metapsicológica

\footnotetext{
* 0 que aqui é apontado como um mero exemplo comparativo entre as três traduções diretas da obra de Freud ao português brasileiro é exaustivamente abordado em outro artigo de mesma autoria "As 'derivas' de um conceito em suas traduções: o caso do Trieb freudiano", atualmente sob análise para sua publicação em outro importante periódico acadêmico brasileiro.
} 
Tavares, P. H. M. B. - As novas traduções de Freud feitas diretamente do alemão: estilo e terminologia

do inconsciente. Por este motivo a escolha recai sobre o neologismo oriundo do francês e já usual na psicanálise brasileira "pulsão", que, apesar de menos compreensível do que instinto tem a vantagem de remeter foneticamente a algo que "pulsa" e a "impulsão" (HANNS 2006).

Já Paulo César de Souza, crítico ferrenho da tradução francesa de Laplanche e grande admirador da versão de Strachey ("... das traduções atualmente disponíveis... a Standard é ainda a melhor..." SouzA, 1999), insiste em instinto colocando o termo entre aspas para diferenciar do Instinkt, termo alemão que aponta de fato para a acepção fundamentalmente criticada de determinismo biológico que o termo veicula na língua portuguesa. Em sua defesa remete o leitor à origem etimológica do termo em "instigar, aguilhoar, estimular". Reforça sua opção por instinto em detrimento de pulsão com o (no mínimo) inusitado comentário:

O mesmo ponto de vista foi saborosamente expresso por um amigo homossexual, numa ocasião em que Ihe perguntei o que achava do termo "pulsão". Ele respondeu "Pulsão têm os anjos, meu querido; gente tem instinto" (registro o fato da sua homossexualidade porque é freqüente (sic) os homossexuais terem uma percepção mais penetrante da sexualidade - própria ou alheia) (idem).

Curiosamente, percebemos em outro caso, Hanns aderir mais às tradições francesas e Souza às soluções da versão inglesa dos Strachey. É o que ocorre com 0 também fundamental termo Verdrängung. Para Hanns Verdrängung é recalque, tão próximo de refoulement (tradução francesa) e para Souza repressão, tão próximo de repression (tradução inglesa). Souza chega a traduzir kultur por civilização tal qual o faz Strachey como o termo civilization.

Renato Zwick, por sua vez, adota para o Trieb uma opção bastante original e ousada por impulso. Em uma tradução com parcas anotações percebemos neste tradutor uma preocupação com o leitor não iniciado, ou talvez uma tentativa de se fazer valer do léxico coloquial da língua 
Tavares, P. H. M. B. - As novas traduções de Freud feitas diretamente do alemão: estilo e terminologia

portuguesa para se aproximar da melhor forma possível do termo freudiano. Sua publicação de Das Unbehagen in der Kultur (O Mal-Estar na Cultura) é acrescida de um breve apêndice "Sobre a tradução de um termo empregado por Freud" no qual utiliza o dicionário de Hanns, alegando que o substantivo Trieb derivado do verbo treiben significa 'impelir, impulsionar, tocar para a frente'" (ZwICK 2010).

O tradutor procura com isso superar a dicotomia certamente colonialista de aderir ou à tradição anglo-saxã, e traduzir Trieb por instinct (instinto), ou a francesa que impõe o inusitado pulsion (pulsão, para nós). Em uma bela metáfora mitológica, aludindo à bravura do astuto Odisseu entre dois gigantescos monstros marinhos argumenta:

Entre o Cila de um termo impreciso (instinct e por extensão "instinto" parece mais adequado para verter o alemão instinkt) e o Caríbdis de um horríssono neologismo (pulsion), acreditamos que haja uma terceira possibilidade que consiste simplesmente em atentar para os sentidos do termo alemão e buscar o seu equivalente em nosso idioma. Por essa razão propomos a tradução de Trieb por "impulso", termo que, parece-nos, cobre perfeitamente os vários matizes de sentido da palavra alemã (ZWICK in FREUD 2010).

A ousadia de Zwick é por alguns motivos louvável, mas principalmente por ser a primeira autêntica preocupação de um tradutor de Freud em buscar no nosso léxico e não nas tradições estrangeiras (inglesa/norte-americana, francesa ou espanhola/argentina) o termo mais adequado ou mais próximo de uma equivalência. A opção por impulso de fato resolve a ambiguidade inerente ao Trieb, entre o biológico e o cultural. Não causa estranhamento afinal que digamos ao mesmo tempo "impulso nervoso" em um texto médico e "impulso consumista" em um texto sociológico. Este parece ser um poderoso trunfo para sua defesa.

Entretanto, a ousadia de Zwick, que previu críticas "desdenhosas" dos fascinados pelos jargões, sobretudo dos iniciados na arte freudiana, talvez não tenha levado em conta um aspecto do vocábulo impulso que não "cobre 
Tavares, P. H. M. B. - As novas traduções de Freud feitas diretamente do alemão: estilo e terminologia

perfeitamente" a acepção freudiana de Trieb. Em Triebe und Triebschicksale (1914), texto mais diretamente comprometido com a definição do conceito, Freud esclarece que "o Trieb, entretanto, nunca opera como uma força de impacto, mas sempre como uma força constante (konstante Kraft)". Se a crítica ao instinto era pelo uso que se faz, no alemão, de Instinkt, Freud utiliza Impuls ou mesmo Antrieb em sua língua para tratar também de uma força momentânea, passageira, abrupta, como de fato no nosso termo impulso parece ser o caso.

Instinto, pulsão, impulso ou outro termo ainda? Ao que tudo indica, os debates seguirão em aberto e tendem à expansão.

\section{Referências bibliográficas}

Adorno, F. Le style du Philosophe, Paris: Éditions Kimé, 1996 p. 16.

Bettelheim, B. Freud and Man's Soul. Nova Iorque: Knopf, 1983 p. 46.

CARone, M. Freud em Português: Uma tradução Selvagem. in SouzA, Paulo César de (org.) Sigmund Freud e o Gabinete do Dr. Lacan. Brasiliense: São Paulo, 1989 pp. 160-1.

Bourguignon, A.; COTet, P.; LAPLANChe, J.; Robert, F. Traduire Freud. Paris: PUF, 1989 p.23-24.

FreUd, S. Das Unheimliche, in Gesammelte Werke - Chronologisch geordnet. Frankfurt am Main: Fischer Verlag, 1919/ 1999, p.242-243.

. Die Traumdeutung in Gesammelte Werke - Chronologisch geordnet. Frankfurt am Main: Fischer Verlag, 1900/ 1999, p.283.

. Triebe und Triebschicksale in Gesammelte Werke - Chronologisch geordnet, Frankfurt am Main; Fischer Verlag, 1915/ 1999, p. 212.

. Zur Psychopathologie des Alltagslebens, in Gesammelte Werke Chronologisch geordnet; Frankfurt am Main: Fischer Verlag, 1901/ 1999, p. 32.

HanNS, L. Dicionário Comentado do Alemão de Freud. Rio de Janeiro: Imago, 1996, p. 339. 
Tavares, P. H. M. B. - As novas traduções de Freud feitas diretamente do alemão: estilo e terminologia

- Comentários do Editor Brasileiro. In: Obras Psicológicas de Sigmund Freud - Volume 1 - Escritos sobre a Psicologia do Inconsciente. Rio de J aneiro: Imago, 2004, p. 144.

HouaISS, A.; VILLAR, M.S. Et al. Dicionário Houaiss da língua portuguesa. Rio de J aneiro: Objetiva, 2001.

Laplanche, J.; Pontalis J.B. Vocabulário da Psicanálise, São Paulo: Martins Fontes, 2001, p. 457-8.

Mahony, P. Freud as a Writer. Nova Iorque: Yale University Press, 1987 p.7.

MonteIRo, M.P. Tradução: Um ato de Criação. Revista Brasileira de Psicanálise v. 43, n. 1, p. 43, 2009.

MUSCHG, W. Freud als Schriftsteller. In: Die Zerstörung der deutschen Literatur. Berna: Diogenes. 2009, p.556-595.

Schönau, W. Sigmund Freuds Prosa - Literarische Elemente seines Stils. Giessen: Psychosozial-Verlag, 2006, p. 8.

SouzA, P.C. As Palavras de Freud - 0 Vocabulário Freudiano e suas Versões. São Paulo: Ática, 1999, p. 31,266, 252.

TAVARES, P.H.M.B. Freud \& Schnitzler - Sonho Sujeito ao Olhar. São Paulo: Annablume, 2007, p. 98-100.

Villareal, I. As Traduções de Freud para o Espanhol. In: ORSTON, D.G. (Org.) Traduzindo Freud. Rio de J aneiro: Imago, 1992, p.145-9.

WoLFSON, L. Translating Freud - A Historical Experience. In: Translation J ournal, v.10, n. 4, out. 2006. . Disponível em, «ttp:// translationjournal. net/journal/ >. Acesso em: 22 de junho de 2011.

ZWICK, R. Sobre a tradução de um termo empregado por Freud. In: FREUD, S. 0 Mal-Estar na Cultura. Tradução de Renato Zwick. Porto Alegre: L\&PM, 2010, p. 190-191. 